\title{
AS BIOTECNOLOGIAS E OS DESAFIOS PARA O DIREITO: A DIGNIDADE DA PESSOA
}

HUMANA EM FOCO

Geilson Nunes ${ }^{1}$

Matheus Freitas ${ }^{2}$

\section{RESUMO}

O presente artigo teve como objetivo proceder um estudo do fenômeno tecnológico da biotecnologia, tendo como problemática seus efeitos na vida das pesssoas sob a ótica da dignidade da pessoa humana. Para tanto, inicialmente procurou-se destacar os princípios da dignidade da pessoa humana e seus direitos e garantias fundametais. Na sequência, destaque se deu aos aspectos da biotecnologia, seus impactos na vida das pessoas, fazendo um parelelo com a salvaguarda da dignidade da pessoa humana. Como método de pesquisa optou-se pelo dedutivo, e como metodologia, uma pesquisa essencialmente bibliográfica, em doutrinas que tratam o assunto e na legsislação pertinente.

Palavras- chave: Biopoder. Dignidade Humana. Sáude. Tecnologias. Vida.

\section{BIOTECHNOLOGY AND THE CHALLENGES FOR LAW: THE DIGNITY OF THE HUMAN PERSON IN FOCUS}

\begin{abstract}
The present article study the technological phenomenon of biotechnology, and the problematic effects on the lives of people and dignity of the human person. We initially sought to highlight the principles of the dignity of the human person and their fundamental rights and guarantees. In the following sequence, the aspects of biotechnology, its impacts on people's lives, were highlighted, making a parlele with the safeguard of the dignity of the human person. As a research method, the deductive method was chosen as a bibliographical research, in doctrines that deal with the subject and in the pertinent legislation.
\end{abstract}

Keywords: Biopower. Human dignity. Cheers. Technologies. Life.

\section{INTRODUÇÃO}

O presente estudo tratará do Biotecnologia como uma nova forma tecnológica de atuar sobre a vida das pessoas, através de suas interfaces como a Nanotecnologia ligada à saúde que, tem por finalidade dar uma maior qualidade na vida das pessoas que necessitam de tratamento a saúde. Assim, procurará demonstrar que os sistemas sociais estão em constante evolução, devendo

\footnotetext{
${ }^{1}$ Doutorando em Direito e Mestre em Direito pela Universidade de Marília- UNIMAR - SP, Especialista em Administração Pública pela Fundação João Pinheiro, BH - MG, possui graduação em Direito pela Fundação Carmelitana Mário Palmério (2015) e graduação em Ciências Militares com ênfase em defesa Social (Curso de Formação de Oficiais )- Polícia Militar do Estado de Minas Gerais (1999), atualmente é Tenente Coronel PM. Professor de Direito Penal, Constitucional, Processo Penal e Criminonologia no Instituto Master de Ensino Presidente Antônio Carlos - IMEPAC - Araguari- MG. Email: capgeilson41@ gmail.com

${ }^{2}$ Tabelião de Notas e Oficial de Registro Civil das Pessoas Naturais no Estado de São Paulo, ex- Advogado, atuante nas áreas de Direito Administrativo e Tributário. Mestre em Direito pela UNIMAR-SP. Graduado em Direito pela Universidade Católica de Pelotas/RS. Email: cartfreitas@ gmail.com.
} 
o direito de adaptar a esta realidade, procurando demonstrar o que é esta nova tecnologia emergente e seus aspectos estruturantes e como ela está se amoldando às outras áreas da ciência e como isto pode trazer efeitos positivos e negativos quando se tratar de proteção da dignidade da pessoa humana, buscando alinhar seus objetivos em benefício da sociedade, evidenciando a máxima relação desse mecanismo como operador dos direitos e garantias fundamentais do cidadão.

A problemática da pesquisa ancorar-se-á em apontar de que maneira a Biotecnologia poderá ser útil para garantir a defesa dos interesses da sociedade, no que tange ao fomento de pesquisas, instrumentos, fármacos e outros destinados à saúde humana e sua máxima relação com os a dignidade da pessoa humana e os direitos fundamentais.

Neste sentido, como melhor forma de ilustrar a pesquisa, percorreremos inicialmente no primeiro capítulo tratando da dignidade da pessoa humana, direitos humanos e os direitos e garantias fundamentais, procurando dar elementos teóricos ao assunto em face de comporem as bases estruturais dos demais princípios, fazendo um alinhamento com as novas tecnologias, mormente a Biotecnologia enquanto atuando na vida das pessoas e questionar se este avanço tecnológico só traz benefícios ou colidem com interesses maiores da dignidade humana com vistas às gerações futuras e a preocupação com o aumento das desigualdades sociais que podem advir. .

Posteriormente, no segundo capítulo a pesquisa trará os aspectos da evolução da sociedade e a necessidade de adequação do direito e, o estudo a respeito das biotecnologias e seus desdobramentos, demonstrando elementos conceituais e seus aspectos no campo da bioética, apontando seus efeitos positivos para o avanço da ciência atuando na vida e na saúde das pessoas, como também o questionamento quanto seus impactos no que tange à dignidade da pessoa humana enquanto bem indisponível.

Quanto ao objetivo a ser alcançado, este se refere à tentativa de aclarar este debate entre as novas tecnologias da vida e sua interface com a dignidade da pessoa humana, no sentido de expor as vantagens de toda esta evolução e, ao mesmo tempo abrir as considerações sobre a realidade dos efeitos que pode surgir concretamente no campo da dignidade humana com vistas à proteção das gerações futuras.

Para a obtenção dos resultados almejados no presente artigo, usaremos um método de abordagem dedutiva que consiste na observação das teorias maiores para se alcançar os resultados propostos na problemática em tela e, por conseguinte, uma conclusão do que se consignou na pesquisa.

Revista de Direitos Humanos e Efetividade | e-ISSN: 2526-0022 | Porto Alegre | v. 4 | n. 2 | p. $16-34$ | Jul/Dez. 2018 
No que se refere ao método de investigação utilizado, correspondente às fontes elencadas, nosso estudo será delineado com referencial teórico bibliográfico doutrinário que trata do assunto, acoplado ao amparo constitucional, a fim de demonstrar que o tema proposto tem vetor de concretização da dignidade da pessoa humana e dos direitos fundamentais, razão do princípio estruturante do Estado Democrático de Direito.

\section{DIGNIDADE DA PESSOA HUMANA SOB A ÓTICA DOS PRECEITOS DAS NOVAS TECNOLOGIAS DE VIDA}

A dignidade da pessoa humana, princípio basilar intimamente ligado aos Direitos Humanos, ganha contornos importantes para a construção e manutenção do Estado Democrático de Direito, hoje alvo de conquista da sociedade moderna e, nesta linha, a Constituição da República Federativa do Brasil/88 inicia, proclamando em seu art. $1^{\circ}$, inciso III, ser a dignidade da pessoa humana o principal fundamento da República.

Adorno (2009, p. 81) esclarece que no plano jurídico, poder-se-ia dizer que a dignidade da pessoa humana constitui o direito inderrogável por excelência, mesmo quando strictu sensu não seja ela mesma um direito, senão a fonte de todos os direitos. A dignidade, não é ao contrário uma realidade pré-jurídica em seu conjunto. Em todos os casos, a raiz comum dos direitos é a dignidade inerente a todo ser humano. Esta última precisão tem duas consequencias importantes. A primeira, é que os direitos fundamentais não são uma simples concessão da autoridade política e por isso, não podem ser caprichosamente por ela retirados. A segunda é que os direitos humanos são iguais para todos, se eles derivam da dignidade humana, e esta, por definição, é comum a todo indivíduo e todos o seres humanos possuem os mesmos direitos fundamentais.

Sobre o tema, diversos estudos apontam seus fundamentos e, nas palavras de Sarlet (2009, p. 109), pode ser considerado como o fundamento de todo o sistema de direitos fundamentais, na exata ordem de dele emanarem o sentido e as exigências para que todo o sistema seja interpretado nas finalidades de atendimento aos preceitos primordiais da mantença da dignidade da pessoa humana.

Bonavides (2000, p. 573), em suas lições, diz que a nova universalidade dos direitos humanos os coloca assim, desde o princípio, num grau mais alto de juridicidade, concretude, positividade e eficácia e na mesma linha, Bobbio (1992, p.21), destaca que os direitos humanos e as liberdades fundamentais são globalmente respeitadas a partir do momento que seus fundamentos são reconhecidos universalmente, e Sarlet (2009, p. 109) bem aponta que a humanidade partilha de valores comuns, e que o princípio da dignidade da pessoa humana pode ser considerado como o fundamento de todo o sistema de direitos fundamentais, na exata ordem de dele emanar o sentido e as exigências para que todo o sistema seja interpretado nas finalidades de atendimento aos preceitos primordiais da mantença da dignidade da pessoa

Revista de Direitos Humanos e Efetividade | e-ISSN: 2526-0022 | Porto Alegre | v. 4 | n. 2 |

p. 16 - 34 | Jul/Dez. 2018 
humana.

Bonavides (1999, p. 587) adverte ainda:

Os direitos fundamentais são a sintaxe da liberdade nas Constituições e, com eles, o constitucionalismo do século XX logrou a sua posição mais consistente e característica, porquanto extrapolaram a relação cidadão- Estado, adquirindo uma dimensão objetiva, de conteúdo aberto e indeterminado, até então ignorada, não pertencente nem ao Direito Público, e tão pouco ao Direito Privado, mas que compõe e orienta de todo ordenamento jurídico-constitucional de cúpula.

O debate filosófico e doutrinário sobre a dignidade da pessoa humana ganha muito relevo em face de sua importância para a mantença da instiuições e nesta linha, Adorno $(2009$, p. 82) destaca que apesar da dificuldade que representa definir dignidade humana, uma certa aproximação conceitual à mesma é possível. Pode-se dizer que, com este termo, se faz referência ao valor único e incondicional que tem a existência de todo ser humano, independente de qualquer qualidade acessória que pudesse corresponder por razões de idade, estado de saúde física ou mental, orígem étnica, sexo, condição social ou econômica ou religião. É sua condição humana como tal o que gera um dever de respeito para com o indivíduo, sem que seja exigido nenhum outro requisito adicional.

A este respeito, a própria Declaração Universal dos Direitos Humanos de 1948, em face de atrocidades levadas a efeito contra seres humanos, declara que "todos os seres humanos nascem livres e iguais em dignidade e direitos. Dotados de razão e consciência, devem agir uns para com os outros em espírito e fraternidade".

Todavia, como bem destaca Sarlet (2013, p. 125), o princípio da dignidade da pessoa humana pode ser desdobrado em diversas dimensões e neste sentido, não se pode deixar de reconhecer a sua dimensão histórico-cultural, comunitária e social e não apenas visto como uma declaração de conteúdo ético, na medida em que é dotada de plenitude e eficácia, alcançando, assim, uma condição de valor jurídico fundamental da comunidade.

Nesta senda, considerada o cerne de nosso ordenamento jurídico, tendo em vista a sua função unificadora de todos os direitos fundamentais Reis (2008, p. 58) destaca que a dignidade da pessoa humana deve ser posta como atividade que realiza os direitos pessoais, sendo tarefa do poder público erigir um ordenamento jurídico e social concretizador desse valor irredutível e, como bem aponta Sarlet (2009, p. 67), "é uma qualidade intrínseca e distintiva de cada ser humano que o faz merecedor de respeito, [...] um complexo de direitos e deveres fundamentais" [...].

A dignidade da pessoa humana sai da esfera da esfera da abstração e entra no campo de sua real concretude, estando presente nos atos e ações de cada ser humano e por isto, pode se tornar alvo de violações diversas, perfeitamente identificáveis no cotidiano da sociedade moderna.

Portanto, nas palavras de Sarlet (2007,p. 364) existe uma dificuldade em estabelecer uma pauta

Revista de Direitos Humanos e Efetividade | e-ISSN: 2526-0022 | Porto Alegre | v. 4 | n. 2 |

p. $16-34$ | Jul/Dez. 2018 
de violações à dignidade da pessoa humana e assim, tanto a doutrina quanto a jurisprudência, na corrida para uma definição jurídica de dignidade, cuidam de estabelecer parâmetros e critérios básicos afim de se aproximar de uma definição mais concreta deste princípio, ainda que, isto não seja uma definição consensualmente aceita em face da amplitude o assunto, caracterizado pela ambiguidade e porosidade, não sendo prudente uma conceituação fixa, pois, em sendo, estaria em colisão com os diversos valores das democracias modernas.

No que tange à qualidade de status jurídico a que é alçada a dignidade da pessoa, pode ser observado que ela não é inserida no rol dos direitos e garantias fundamentais, ganhando sim a condição de princípio fundamental da República e neste sentido, Sarlet (2011, p. 53) considera que na qualidade de princípio fundamental, a dignidade da pessoa humana constitui valor-guia não apenas dos direitos fundamentais, mas de toda ordem jurídica constitucional e infraconstitucional.

É notório que a judicialização dos direitos fundamentais ganha notoriedade ainda mais frente a inércia e omissão dos poderes públicos e nesta linha de raciocínio, Revenga (2009, p. 13) argumenta que o Brasil tem passado por um estágio de afirmação dos direitos constitucionais, construídos na afirmação de efetivo exercício de cidadania, decorrentes de um maior controle judicial ocorridas no Supremo Tribunal Federal e nas demais instâncias do Poder Judiciário.

Assim, nos julgados atuais do Supremo Tribunal $\mathrm{Federal}^{3}$ uma vasta jurisprudência sobre o princípio da dignidade da pessoa humana e sua estreita relação com os direitos fundamentais e tem entendido também ser a dignidade da pessoa humana como principal vetor e fonte de inspiração de todo ordenamento jurídico, e sua fundamental importância para as decisões judiciais.

Nesta esteira, exemplificando, Sarlet (2011, p. 67) destaca a vedação da tortura e tratamento desumano, a proibição da redução do ser humano como objeto de ação estatal, regulando o uso de algemas; no campo dos direitos sociais, uma atenção aos chamados mínimo existencial e sua vedação de tributação e proibição de confisco, incumbindo também ao Estado a manutenção deste mínimo existencial, dentre outras ações e prestações positivas.

Referindo-se ao importante papel da normas constitucionais e infraconstitucionais na garantia dos direitos fundamentais e da dignidade da pessoa humana, Canotilho (2003, p. 49) destaca que deve-se preservar a integridade física e espiritual do homem como atributo irrenunciáveis, apontando também o que ele chama de "libertação da angústia de existência" do ser humano, sendo necessário que lhe destine a possibilidade de trabalho, emprego, mínimo existencial através de mecanismos assistenciais básicos para a garantia de sua sobrevivência.

De modo genérico, pode-se afirmar que a dignidade da pessoa humana é um bem imaterial,

\footnotetext{
${ }^{3}$ A duração prolongada, abusiva e irrazoável da prisão cautelar do réu, sem julgamento de causa, ofende o postulado da dignidade da pessoa humana e, como tal, consubstancia constrangimento ilegal, ainda que se trate de crime grave." STF (Segunda Turma) Habeas corpus 87.676.5 - Espirito Santo, rel. Min. César Peluso, julgamento em 06/05/2008.
} 
espiritual, ligado diretamente à essência do ser humano, à sua condição psíquica, interior. É um bem eterno que não finda com a morte, mas que, ao contrário, prolonga-se pela eternidade. É uma condição de todo ser humano, independentemente de sua raça, cor ou religião, valendo registrar que é qualificada como algo inerente ao ser humano, como grande parte doutrinária assim a tipifica, atributo chancelado pela indisponibilidade, inerente a qualquer pessoa, mesmo aquelas que cometem os atos mais vis contra seu próximo.

Por estar inserida na ordem jurídica, fica evidente que a judicialização dos direitos fundamentais ganha mais notoriedade frente à inércia e à omissão dos poderes públicos e, nessa linha de raciocínio, Revenga et al (2009, p.13), argumentam que o Brasil tem passado por um estágio de afirmação dos direitos constitucionais, construídos na afirmação de efetivo exercício de cidadania, decorrentes do maior controle judicial ocorridas no Supremo Tribunal Federal e nas demais instâncias do Poder Judiciário.

Demostra-se, no exposto até aqui, a importância principiológica da dignidade da pessoa humana e dos direitos e garantias fundamentais. É importante, para a sua eficácia, uma postura ativa do Estado por meio de políticas públicas, na busca da conquista e fruição dos direitos pelo cidadão, para que os objetivos da república sejam alcançados e para isto, deve haver um desenvolvimento econômico, aliado a um desenvolvimento social, para a efetiva instalação da Justiça social, o que passamos a discorrer na próxima seção.

No que se refere à dignidade da pessoa humana e o debate bioético envolvendo as novas tecnologias a exemplo da Biotecnologia, Adorno (2009, p. 81) destaca que a busca de um equilíbrio adequado entre a liberdade e a dignidade da pessoa constitui um dos desafios mais complexos da bioética. Ressalta que o respeito à dignidade da pessoa humana emerge no recente biodoreito como marco irrenunciável em que se deve desenvolver a atividade biomédica, tanto no âmbito clínico como no da pesquisa científica e que, a diginidade, ainda quando resulte dificilmente definível, é uma característica bem real dos seres humanos e não uma mera hipótese metafísica e destaca o autor:

Esta explicação de dignidade se traduz em uma exigência de não instrumentalização da pessoa humana e é sumamemte esclarecedora no campo da bioética. Significa por exemplo que não se pode sacrificar uma vida de uma pessoa para salvar a que precisa de um órgão vital; não pode submeter um indivíduo a experimento científico sem o seu consentimento ou quando o expõe a perigo de vida. Assim, através da exigência de não instrumetalização da pessoa, o princípio da dignidade permite fixar limites éticos às intervenções biomédicas no ser humano. (ADORNO, 2009, p. 82).

Nesta linha de pensamento e alertando sobre a importância da defesa e proteção da dignidade da pessoa humana e dos direitos humanos, com a preocupação de não tornar a vida humana um mero objeto tecnológico, Piovesan (2009, p. 108) assevera que os direitos humanos se inspiram na dupla vocação de afirmar a dignidade humana e prevenir o sofrimento humano e que o ser humano é ao mesmo tempo um

Revista de Direitos Humanos e Efetividade | e-ISSN: 2526-0022 | Porto Alegre | v. 4 | n. 2 |

p. $16-34$ | Jul/Dez. 2018 
início e um iniciador e que é possível modificar pacientemente o deserto com as faculdades da paixão e do agir. Deve a ética dos direitos humanos trabalhar com o idioma da reciprocidade que vê no outro um ser merecedor de igual consideração e profundo respeito, dotado do direito de desenvolver as suas potencialidades de forma livre e de forma plena.

Assim, as novas tecnologias, como a Biotecnologia ao adentrar no campo da vida das pessoas deve ser balizada pelo princípio estruturante da dignidade da pessoa humana e dos direitos humanos quem segundo Ramos (2014, p. 17) estes últimos consistem em um conjunto de direitos considerado indispensável para uma vida humana pautada na liberdade, igualdade e dignidade. Os direitos humanos são os direitos essenciais e indispensáveis à vida digna, não tendo um rol predeterminado desse conjunto mínimo de direitos essenciais e, na mesma linha de pensamento, Barreto $(2009$, p. 2) destaca que a vida humana, portanto, torna-se possível na medida em que cada indivíduo possa ser considerado moralmente por atos praticados, que tenham repercussões em suas relações sociais e, no que tange às Biotecnologias pondera:

\begin{abstract}
As biotecnologias, ao mesmo tempo que abrem perspectivas de melhoria da vida humana, também podem trazer efeitos nefastos para a vida humana. Técnicas que tinham por objeto principal a melhoria da saúde do homem produziram, no exercício da medicina e nas possibilidades que abriram para manipulações, uma gama de intervenções que em vez de curativas, tornarfam-se fonte de patologia.[...] Os avanços da biotecnologia trouxeram consigo uma gama de questionametos éticos por demonstrar a insuficiência teórica dos fundamentos da teoria clássica da responsabilidade e da justiça. (BARRETO, 2009, p. 18).
\end{abstract}

Em sintese, as novas tecnologias, dentre elas a Bioteconologia, deve ter seu parêmetro na dignidade da pessoa humana. O avanço tecnológico é salutar e necessário para o desenvolvimento do homem e da sociedade globalizada, contudo o Direito e a Justiça surgem como instrumentos de regulação para que os desafios éticos e morais na sociedade tecnocientífica, possam ser direcionados na senda de uma abordagem que exija de dos atores do sistema o julgamento de atos sociais e de suas consequencias jurídicas e sua responsabilização, pois, deve se ter uma preocupação ética com as aplicações dos novos conhecimentos científicos e teconológicos, mormente quando se está em jogo a saúde e a vida humana e para tanto, todo desenvovimento tecnológico deve ser balizado por princípios que estejam ancorados na dignidade da pessoa humana.

\title{
3 AS BIOTECNOLOGIAS : UM OLHAR SOBRE SUA INCIDÊNCIA NA VIDA E NA SAÚDE DAS PESSOAS E AS BALIZAS ÉTICAS FUNDADAS NA DIGNIDADE HUMANA
}

A sociedade da pós-modernidade vive um momento de intensas transformações em sua estrutura social, acarretadas pelo avanço de todos os seus extratos e sistemas, na imprevisibilidade das diversas situações que surgem a cada instante, provocando uma complexidade que não prescinde de prévio 
planejamento, mas que se instala de forma dinâmica.

Neste sentido, destaca Luhmann (1983, p. 45):

O homem vive em um mundo constituído sensorialmente, cuja relevância não é equivocadamente definida através do seu organismo. Desta forma, o mundo apresenta ao homem uma multiplicidade de possíveis experiências e ações, em contraposição ao seu limitado potencial em termos de percepção, assimilação de informação, e ação atual e consciente.

É notório que a sociedade se evoluiu no tempo, entrando na era da modernidade, tornando-se imperiosa uma adequação do Direito que além de sua função garantidora e repressiva, assume o papel de articulador e organizador da sociedade e, nesta linha de raciocícinio, Ferraz Júnior (2017, p.57) enfatiza que o Estado cresceu e aparece atualmente mais como produtor de serviços de consumo social, regulamentando a economia e a produção da riqueza, sendo necessária a montagem de um complexo arcabouço jurídico para organizar a sociedade, direcionando-a e dando sustentabilidade na produção de riquezas, coordenação das atividades econômicas, estímulos e subsídios. Salienta ainda o autor que a própria sociedade alterou-se em complexidade, com aparecimento de fenômenos novos, como organismos internacionais, empresas multinacionais, fantásticos sistemas de comunicação e outras tecnologias e ainda destaca:

As sociedades estão em transformação e a complexidade do mundo está exigindo novas formas de manifestação do fenômeno jurídico e que este formato instrumental, uniformizado e rígido do direito venha implodir e se tornar um direito de muitas faces de acordo com cada peculiaridade que se apresente (FERRAZ JÚNIOR, 2017, p.7).

Assim, na esteira de complexidade social moderna, onde os sistemas autodesenvolvem-se na busca da qualificação e crescimento, a cibernética surge como um modo de reduzir as complexidades sociais, em face de sua rápida evolução e organização nas sociedades atuais, inserida em todos os níveis da organização e provocando as mudanças e desenvolvimentos que chegam para ficar e, como bem destaca Ferraz Júnior (2017, p. 8) “a revolução tecnológica, que implica a substituição das máquinas por aparelhos eletrônicos cada vez mais miniaturizados em unidade de convergência técnica, aponta novos caminhos".

Seguindo esta premissa, afirma Lima (2009, p. 39): "O surgimento do Estado Moderno é um marco desse processo evolutivo até a modernidade. A diferença da sociedade moderna ás demais formas sociais está justamente na complexidade, ou melhor, na elevada complexidade. [...]".

Nessa linha de complexidade social inaugurada, a evolução da internet surge na sociedade moderna como uma forma de solução das complexidades instaladas e aponta caminhos diversos, que atinge a todos os sistemas, o jurídico, econômico cultural e social, criando em especial para o Direito uma necessidade de se adequar e fazer frente à realidade, assumindo o papel de articulador e organizador do estrato social.

Como bem destaca Santos (2005, p. 135), a complexidade do mundo reside, assim, na dimensão

Revista de Direitos Humanos e Efetividade | e-ISSN: 2526-0022| Porto Alegre | v. 4 | n. 2 |

p. $16-34$ | Jul/Dez. 2018 
do tempo. Um sistema que opera com sentido, e que está sujeito ao tempo, concebe constantemente o mundo como um mundo de possibilidades de viver e de agir, projetadas no futuro.

Por sua vez, Ferraz Júnior (2017, p. 57) enfatiza que o Estado cresceu e aparece atualmente mais como produtor de serviços de consumo social, regulamentando a economia e a produção da riqueza, sendo necessária a montagem de um complexo arcabouço jurídico para organizar a sociedade, direcionando-a e dando sustentabilidade na produção de riquezas, coordenação das atividades econômicas, estímulos e subsídios.

Assim, levando-se em conta que esta estas mudanças são inerentes aos sistemas sociais e fazem parte do próprio desenvolvimento da humanidade e da globalização, Torres (2014, p.101) acrescenta que esta gama de modificaçãoes nos diversos níveis, exige uma reorganização social para se adaptar às novas realidades tecnológicas e científicas, alinhadas à nova ordem mundial que colocam a vida e todas as suas manifestações e expressões no centro das mudanças e debates acadêmicos e políticos e ainda leciona no seguinte sentido:

Para o debate ético e bioético, a eutanásia, o aborto, as novas técnicas de reprodução in vitro, a medicina do desejo, a experimentação com células-tronco, os desenvolvimentos em genômica e suas aplicações tendem a se concentrar no corpo humano, em uma reconsideração e debate sobre a natureza humana. $\mathrm{O}$ debate ampliou-se para incluir considerações sobre os recursos necessários para sustentar os sistemas de saúde e as políticas de bem-estar social, bem como o papel da intervenção do Estado (TORRES, 2014, p.101).

Os avanços nas áreas de ciências e tecnologia passaram a se configurar como essenciais no desenvolvimento econômico, cultural e social de um país. E o ensino de ciências também apresentou determinado crescimento, fundamentando vários movimentos de transformação do ensino. Conforme Krasilchik (2000, p. 85), fato histórico que evidenciou este crescimento foi quando durante a guerra fria os cursos de ciências buscavam incentivar jovens talentos a seguir carreiras científicas.

Neste campo de desenvolvimento tecnológico, surge a biotecnolgia, uma nova modalidade científica que tem revolucionado a sociedade em suas várias frentes e, neste sentido, Casabona (2007, p.30) destaca que a biotecnologia moderna dispões de técnicas muito precisas e eficazes, em particular, está abrindo novas realidades, sobretudo, perspectivas muito promissoras para diversos campos da indústria, da agricultura, da alimentação, da saúde, do meio ambiente, entre outros e destaca ainda:

Conquentemente, a capacidade de interferir na matéria viva por meio de biotecnologias tornou-se muito maior, assim como a velocidade com que as transformações podem ocorrer. No entanto, há ocasiões em que alguns efeitos das biotecnologias são imprevisíveis e, por isso, nem sempre são controláveis (CASABONA, 2007, p.30).

Assevera ainda Casabona (2007, p.30) que o poder legislativo enfrenta um problema em relação a este assunto que, de certa maneira, pode ser classificado como novo a considerar as incertezas de apontar 
os verdadeiros riscos contra os quais devemos nos previnir e que podem estar vinculados a essas tecnologias, de acordo com a denuncia de alguns grupos sociais, no entanto, foram se abrindo algumas formulas, que tiveram utilidade no mundo jurídico, com a finalidade de orientar as ações dos poderes públicos em torno desta incerteza, uma vez descartada a opção mais simples da inibição ou proibição, já que carecem de fundamento.

No que se refere à postura do Direito frente a esta tecnologia, o autor citado faz as seguintes considerações sobre a a intervenção do direito nos diversos aspectos da biotecnologia:

I O objetivo de garantir a liberdade de pensamento, criação e produção científicas. Como se sabe, a consideração de tais liberdasde, como direitos fundamentais, se estendeu amplamente da atualidade, portanto, o ordenamento jurídico deveria dispor de recursos oprtunos para garantir o livre exercício desse direito.

II Finalidade de promover a investigação cientïfica e tecnológoca em geral, estabelecendo um quadro jurídico adequado para as diversas necesidades que o setor apresenta a fim de compatibilizar a agilidasde que seu extraaordinário dinamismo requer, com a segurança jurídica necessária, conforme sua crescente importância social e eeconômica.

[...].(CASABONA, 2007, p.31).

Nesta mesma linha de racicínio, considerando que este avanço tecnológico é uma caminho que vai ser trilhado pela sociedade em todos os ramos da ciência e que, é inerente à própria natureza humana em sua necessidade de busca constante do novo e, no que tange ao campo da tecnologia que envolve a vida, Berian (2007, p.84) assevera que a revolução que passa o campo da biotecnologia possui importância suficiente para fazer com que nossas sociedades redefinam sua escala de valores par enfrentar esse novo cenário, trazendo consequências para o mundo jurídico que não pode ser independente de outras esferas da atividade humana, sobretudo se levar em conta que sua finalidade é ordenar uma sociedade de acordo com as indicações realizadas em outros âmbitos e que a relação entre as próprias ciências experimentais e o direito, resulta ainda mais evidente que uma interconexão tão completa quanto possível só pode trazer benefícios para ambas.

Tratando sobre o tema, Bergel (2007, p. 356) salienta que o risco está na incerteza científica e, consequentemente, o seu reconhecimento deve constituir o ponto de partida para o debate democrático e para a implementação de políticas públicas de gestão adequadas, considerando que, quanto mais avançam a possibilidades de aplicação de biotecnologia, mais sofisticadas se tornam as formas de análise de risco biológico, que atualmente, é estudado como uma análise de risco, gerenciamento e informação.

Nesta linha de avanços na tecnologia ligada à saúde, a Nanociência e a Nanobiotecnologia ganham campo no sentido de uma melhora na qualidade de vida dos pacientes e conforme destaca Leonel e Souza, (2009, p.3), o desenvolvimento da Nanociência, Nanotecnologia e Nanobiotecnologia concretizam-se graças aos avanços dos estudos e pesquisas nas áreas de ciências da biologia, física, e

Revista de Direitos Humanos e Efetividade | e-ISSN: 2526-0022 | Porto Alegre | v. 4 | n. 2 |

p. $16-34$ | Jul/Dez. 2018 
química. Fatos que marcaram esses avanços foram: A invenção de instrumentos , como o microscópio de varredura por tutelamento eletrônico e microssondas eletrônicas de varredura de visualização e manipulação da matéria.

Fazendo uma abordagem técnica sobre a assunto, Pantoja (2016, p.3), aponta que a nanociência se trata do estudo e conhecimento de técnicas que compõem uma nova abordagem de investigação e desenvolvimento por meio do estudo de fenômenos e pela manipulação de materiais nas escalas atômica e molecular e se destaca, pois, é um campo amplo e interdisciplinar, com envolvimento de diversas áreas, não se trata de uma tecnologia específica, e sim um conjunto de técnicas que se baseiam em princípios da química, física, biologia, engenharia de materiais, computação, medicina, e outros.

Conceitualmente, ainda de acordo com Pantoja (2016, p.4), a Nanobiotecnologia é uma aplicação da nanotecnologia nas ciências da vida. Por exemplo, para liberação de Fármacos, biodisponibilidade, liberação controlada, alvos dirigidos e, nesta linha, acrescenta que a tecnologia fornece inúmeras vantagens, como, maior eficácia terapêutica, liberação progressiva e controlada do fármaco, diminuição significativa da toxicidade, direcionamento a alvos específicos e destaca:

Considerando que os medicamentos quimioterápicos para o câncer precisam ser administrados em altas doses para que possam destruir as células tumorais e, sendo altamente tóxicos, acabam afetando também os tecidos normais do organismo, podendo gerar até mesmo um câncer secundário, esta aplicação da nanobiotecnologia assume importância considerável. É uma forma de se obter a maximização do efeito da droga, minimizando seus efeitos colaterais e seus resultados podem representar um grande salto para o combate a esta patologia (PANTOJA, 2016, p. 4).

Lecionando sobre o assunto, Moller (2009, p. 25) salienta que os novos conhecimentos científicos e biotecnológicos adquiridos vêm tornando possível o desenvolvimento de novos fármacos, tratamentos, aparelhos e procedimentos médicos, além de novas formas de reprodução humana e da pesquisa em engenharia genética que permite a manipulação do genoma com fins terapéuticos. E de fato, tais conhecimentos nos permite vislumbrar, senão já usufruir, de significativos benefícios à saúde e de um incremento da qualidade e da expectativa de vida e complementa:

Vivenciamos, assim, um cenário de veloz concretização de muitos anseios: o alívio da dor, a superação da infertilidade, a libertação de doenças, o prolongamento da vida. No entanto, os avanços das ciências biomédicas suscitam uma série de quetionamentos de ordem ética, política e jurídica, acerca do mode de fazer ciência e acerca dos resultados das pesquisas das novas tecnologias à saúde humana e ao ecossistema. Assim, a ciência e seus produtos saem do âmbito restrito da pesquisa, atuação e arbítrio do cientista (e dos laboratórios, industrias farmecéuticas e institutos tecnológicos), para ganhar espaço nas reflexões, seja de estudiosos de áreas duiversas, seja de um público leigo apato a imaginar ou perceber as consequaências- vantagens e riscos - que o espantoso progredir da ciência pode trazser em múltiplas esferas de sua vida. (MOLLER, 2009, p. 25). 
Pode-se perceber que o avanço das novas tecnologias que entram no âmbito da vida humana, são bem vistas quando obsevada pelo foco dos seus benefícios para a qualidade de vida das pessoas, contudo, a de se perquerir até que ponto este avanço não estaria entrando de uma forma incompatível com os valores éticos e morais e atrair consequências negativas ao homem.

Nesta esteira de pensamento, Moller (2009, p. 27) lembra que à ciência cabe desenvolver um papel determinante diante dos avanços e daquilo que propiciam e, uma sociedade informada e ciente dos riscos e benefícios envolvidos na aplicação dos conhecimentos cientíticos e biotecológicos estará apta a pautar a sí própria por um princípio de responsabilidade, exigindo que a produção científica, e a informação acerca de seus possíeveis usos, saia do âmbito restrito da atuação científica e alcance todos os setores sociais.

Portanto, importante destacar as liçoes de Habermas (2010, p. 56) ao lecionar que os desenvolvimentos de grandes repercusões e notariedade e até questionados e temidos da teconologia genética afetam a imagem que se havia construído de nós enquanto ser cultural da espécie , que é o homem e para o qual parecia não haver alternativas e lembra que partir desta perspectiva, impõe-se a questão se a tecnicização da natureza humana altera a auto-compreensão ética de sua natureza de tal modo que não possamos mais nos compreender como seres vivos eticamente livres e maralmente iguais, orientados por normas e fundamentos.

Discorrendo mais sobre este assunto que tem aguçado a mente da comunidade acadêmica e cintífica, Habermas (2010, p. 58) lembra ainda que para os processo vitais do organismo humano, assistidos tecnicamente, os nanotecnólogos projetam, pela fusão do homem à máquina, a imagem de uma estação de produção, que é submetida a uma supervisão e a uma renovação auto-reguladas, além de passar por reparos e aperfeiçoamento constantes.

Surge então neste contexto a preocupação dos diversos ramos da ciência com o debate ético em torno da vida humana e, somente com esta junção das ciências é que se poderá chegar a conceitos e diretrizes para guiar as atividades científicas com foco na dignidade da pessoa humana, surgindo o debate bioético.

Assim, nas palavras de Moller (2009, p. 42), a preocupação ética com as possíveis aplicações dos novos conhecimentos científicos e biotecnológicos à saúde humana e ao ecossistema, bem como com aquilo que já vem sendo feito sem a existência de regulação e controles, fez nascer um novo campo de estudo- a bioética- destinado à reflexão e discussão interdisciplinar e à busca de princípios e parâmetros que pudessem servir de como diretrizes para a relaização de pesquisas e experimentos e o uso de seus resultados, e neste sentido, importante destaque traz Barreto (1999, p. 396):

Identificar o núcleo fundamental da Constituição e os direitos humanos mínimos (fundamentais) como parêmetros normativos, significa pensar o direito como 
estreitamente vinculado aos âmbito da ética, e implica a afirmação de critérios baseados em valores e princípios éticos gerais, de vocação universal.

Seguindo esta linha de raciciocínio e considerando que a Constituição Federal de 1988 tem como fundamento a dignidade da pessoa humana como princípipo estruturante de todos os outros princípios e da ordem estatal e jurídica, não há como pensar em tecnologias que entram no campo da vida humana, sem se atentar aos valores éticos e morais que balizam todos o sistema, destacando que o valor fundamental da vida é prevalente aos demais, por isto, a pensar que estas novas tecnolgias podem afetar diretamente o ser humano, todo amparo deve ser antecedido a considerar que a a falibilidade da vida é natural e até que ponto este avanço da biotecnologia poderia chegar ou pretende chegar.

Conforme as lições de Ferreira e Pedro (2009, p. 177), as novas tecnologias de manipulação da vida, em especial aquelas que operam em nível molecular, acenam com a possibilidade de perfectibilidade indefinida do corpo humano e que, para alguns autores, estaríamos na iminência de uma solução técnica para o sonho milenar da imortalidade, com a possibilidade de aperfeiçoamento indefinido, contudo assevera que as novas tecnologias de manipulação da vida operam em uma escala em que certas diferenças culturalmente relevantes se tornam problemáticas, como aquelas entre o orgânico e o inorgânico, entre o que é matéria e o que é informação, entre o que está vivo e o que é inanimado.

O que fica evidenciado nesta questão onde as novas tecnologias atingem o corpo e a vida das pessoa é a atuação do biopoder que não pode deixar de ser analisado, pois, é um exercício da política sobre a vida biológica e como bem observa Ferreira e Pedro (2009, p. 178), é preciso questionar esse lugar político fundamental que a tecnociência possa ocupar e em quais aspectos e condições pode invadir legitimamente o terreno da vida nua, da vida biológica e isso significa que o biopoder encontra também aqui uma dimensão ecológica que não pode deixar de ser trabalhada.

O fato já comprovado é que todas as mudanças e incrementos de novas tecnologias trazem consigo benefícios e também um considerado efeito colateral, tanto para a vida das pessoas quanto ao meio ambiente e isto leva a questionar a possiblidade de efeitos negativos, a considerar que novos materiais serão produzidos com base em nanociências e quais seriam seus efeitos, pricipalmente de seus dejetos.

Os destaques recentes no progresso da ciência, apontam para uma tendência da interdisciplinariedade, permitindo que o fluxo de informações perpassem por todas as ciências e, conforme escalarecem Ferreira e Pedro (2009, p. 181-182), a própria idéia de uma ciência voltada para a circulação de informação entre o humano, o técnico e o natural, possibilitou a constituição daquilo que veio a se chamar ciências da informação também que a cibernética passasse a ser um paradigma fundamental para a biologia molecular e para a neurociência, e acrescentam ainda os autores: 
As expectativas despertadas pela convergência tecnológica, ou do espaço que poderá ocupar biotecnologia nas sociedades contemporâneas, são muito grandes, sobretudo se considerarmos os cenários que se abrem para a saúde humana. As promessas aqui são significativas. A primeira delas seria o surgimento de uma medicina radicalmente preventiva, e com ela a necessidade de "melhores testes ex vivo e a melhoria das atuais técnicas de laboratório" para permitir medições com maior sensibilidade e especificação.(FERREIRA; PEDRO, 2009, p. 183).

Fica notório que a biotecnologia já ocupa seu espaço de maneira avançada no campo da ciência humana e que diversos experimentos irão ser levados a efeito para que possibilidades múltiplas sejam perseguidas para o alcance de técnicas e tratamentos eficientes na busca de uma vida perfeita e, nesta linha de pensamento, Ferreira e Pedro (2009, p. 184), asseveram que alcançado estes graus de sofisticação técnica, realizar-se-ia o sonho de tratamentos altamente eficientes e direcionados com precisão molecular, ou seja, com biodisponibilidade virtualmente perfeita, oferecendo agora novas intervenções para fazer corpos fisicamente mais fortes, mais espertos, mais duráveis, melhorado mediante o emprego de tecnologia e um novo modo de pensar acerca da saúde.

Os autores acima destacados acrescentam que o entendimento é de que a biotecnologia pode constituir um campo empírico de grande importância para apreciar a pertinência das observações de Foucault (1987, p. 81) o qual destaca que a visão de tecnologias da vida é algo distinto do que hoje caracteriza o paradigma molecular da biotecnologia e ainda esclarece que o corpo humano entra numa maquinaria de poder que o esquadrinha, o desarticula e o recompõe, sendo uma anatomia política, que é também igualmente uma mecânica do poder, fabricando corpos submissos e exercitados, corpos dóceis.

A melhoria na qualidade de vidas das pessoas pelas tecnologias, esta busca pela perfeição e docilidade do corpo, manipulando a vida não deve se direcionar para os conhecidos campos de concentração, onde a busca pela perfeição se atingia pela morte das pessoas no afã da captura de novos conhencimentos, através de atos de soberania capazes de sufragar a cultura tecnológica da sociedade moderna e globalizada.

Nesta linha de raciocínio, Ferreira e Pedro (2009, p. 190) asseveram que ainda que elementos tanatológicos fundamentais podem e devem ser discutidos nas novas tecnologias de manipulação da vida, não é necessário que para isto se tenham campos de concentração como cristalização dos males que afligem a cultura tecnológica.

Salientam ainda Ferreira e Pedro (2009, p.192) há evidentemente os entusiastas que acreditam na resolução de grandes problemas econômicos, médicos, ambientais por intermédio da convergência nanobiotecnológica e das tecnologias que daí prosperam. Abordagens críticas têm reivindicado espaço junto à discussão pública dos horizontes técnicos e sociais que se abrem. Nos países desenvolvidos, esses 
espaços têm sido garantidos de algum modo na elaboração de cenários que venham a orientar políticas governamentais na área.

Resta destacar que argumentos diversos surgirão neste debate ético e bioético que tem aguçado a comunidade científica e traz consigo a responsabilidade do pensamento e da adequação jurídica pelo Direito, em face de todo impacto que pode provocar na vida das pessoas e também no cenário econômico e, este como regulador das condutas sociais deve ser atentar pois, consequências nas futuras gerações poderão ser percepitíveis e até quando esta promessas de perfeição, vida eterna, perfectibildasde de corpos poderá causar desigualdades sociais e ofensas à dignidade da pessoa humana e seus direitos fundamentais

\section{CONCLUSÃO}

A partir da análise do exposto nesta pesquisa, conclui-se:

Demostra-se no exposto até aqui, a importância principiológica da dignidade da pessoa humana e dos direitos e garantias fundamentais, sendo importante para sua eficácia, uma postura ativa e que eles sejam respeitados e que, o desenvolvimento baseado nas novas tecnologias, inclusive as que tratam da vida, tenham como parâmetro a diginidade da pessoa humana, os direitos humanos e os direitos e garantias fundamentais, para a efetiva instalação da justiça social.

Nesta pesquisa, o objetivo se estabeleceu em abordar a Biotecnologia e sua interface com a dignidade da pessoa humana, lançando como objetivo principal um alinhamento destes avanços tecnológicos nas ações e na vida da pessoas, com a finalidade com que estes contribuam com os interesses da sociedade de forma positiva. Como problemática do assunto, abordamos no sentido de apontar de que maneira as bioteconologias podem ser úteis para a melhoria da saúde das pessoas e ao mesmo tempo, ferir preceitos de dignidade humana, impactando as futuras gerações.

Dessa forma, ficou incialmente neste trabalho evidenciado os valores supremos da dignidade da pessoa humana e dos direitos fundamentais, os quais, servem como alicerces para todos os demais valores e deve ser o trilho a ser percorrido para a harmonia de todo o sistema e, quando se inova, trazendo para o seio da sociedade novos valores e preceitos das tecnologias, como as biotecnologias, estas devem estar alinhadas de modo a propiciar benefícios, contudo, balizados pela etica que deve ser inerente.

Na sequência, a pesquisa trouxe as premissas das Biotecnologias, apontando também as Nanobiotecologias, estas inerentes às mudanças sociais e avanços da cibernética que, se voltam para a importância da vitalidade da vida humana, melhoria nos tratamentos de saúde, fármacos, 
na busca corpos perfeitos e velozes, olhando para um futuiro da eternização. Fica evidenciado que trata-se de uma tecnologia que veio para ficar e que vai trazer consigo muitos benefícios para a vida humana, contudo, devem ter as balizas da bioética.

Assim, a presente pesquisa faz esta interface entre as Biotcnologias e a Diginidade da pessoa humana, ressaltando a importância dos avanços tecnológicos para para a qualidade de vida do homem, contudo, deixando o entendimento que atenção deve ser dada quanto a todos os efeitos que serão produzidos, salientando que os valores humanos inerentes ao homem devem ser prevalentes aos interesses das novas tecnologias, principlamente as que atuam no campo da vida como a biotecnologia e que, a dignidade da pessoa humana deve estar protegida em nome das futura gerações e para evitar desigualdades socais em tempos vindouros.

Como referencial teórico, adotou-se o que está exposto em doutrinas, obras literárias modernas sobre o tema, e outras fontes de pesquisa, na busca descortinar a problemática posta. No mesmo caminho, a partir do o método dedutivo de pesquisa, partimos de uma premissa geral com âncora no texto constitucional e chegamos a resposta do problema, podendo concluir que as bioteconologias tem sua vital importância no contexto de desenvolvimento da sociedade e muitos benefícios para a vida e saúde das pessoas são indiscutíveis, contudo, devendo estarem firmados sob os pilares de sustentação da dignidade da pessoa humana e dos direitos e garantias fundamentais, tendo estes valores prevalentes sobre os demais, em nome da igualdade entre as pessoas e a proteção das futuras gerações e que, o ser humano jamais pode ser manipulado como coisa ou objeto de experimentos puramente de interesses mercantis ou outros.

\section{REFERÊNCIAS}

ADORNO, Roberto. Liberdade, e dignidade da pessoa. dois paradigmas opostos ou complementares da bioética?. In: Bioética e responsabilidade. COSTA, Judith Martins; MOLLER, Letícia Ludwig. (orgs). Rio de Janeiro: Forense, 2009, p. 73-93.

BARRETO, Vicente de Paulo. Bioética, responsabilidade e sociedade tecnocientífica. In: Bioética e responsabilidade. COSTA, Judith Martins; MOLLER, Letícia Ludwig. (orgs). Rio de Janeiro: Forense, 2009, p. 1-22.

Bioética, biodireito e direitos humanos. In TORRES, Ricardo Lobo. (org). Teoria dos direitos fundamentais. Rio de Janeiro: Renovar, 1999, p. 383-423.

BOBBIO, Norberto. A era dos direitos. $7^{\text {a }}$ impressão. Trad. Carlos Nelson Coutinho. Rio de Janeiro: Campus, 1992. 
BONAVIDES, Paulo. Curso de direito constitucional, $11^{\circ}$ ed., São Paulo: Malheiros Editores, 2000 .

BERGEL, Salvador Dário. O princípio da precaução como critério orientador e regulador da biossegurança. In : CASABONA, Carlos María Romeo; SÁ, Maria de Fátima Freire de.

Desafios jurídicos da biotecnologia. Belo Horizonte: Mandamentos, 2007, p. 347 - 372.

BERIAN, Inigo de Miguel. A biotecnologia é uma ameaça para o direito? In CASABONA, Carlos María Romeo; SÁ, Maria de Fátima Freire de. Desafios jurídicos da biotecnologia. Belo Horizonte: Mandamentos, 2007, p. 77-106.

CANOTILHO, José Joaquim Gome. Direito constitucional e teoria da constituição. 7.ed., Coimbra: Edições Almedina, 2003.

CASABONA, Carlos María Romeo. O desenvolvimento do direito diante das biotecnologias. In:___ _ SÁ, Maria de Fátima Freire de. Desafios jurídicos da biotecnologia. Belo

Horizonte: Mandamentos, 2007, p. 30 -64.

FERREIRA, Jonatas; PEDRO, Rosa Maria Leite Ribeiro. Biossociabilidade e biopolítica: reconfigurações e controvérsias em torno dos híbridos nanotecnológicos. Redes, v. 15, n. 29, mayo 2009. Buenos Aires, Universidad Nacional de Quilmes Argentina, p. 177-196.

FERRAZ JUNIOR, Tércio Sampaio. Introdução ao estudo do direito. Técnica, decisão, dominação. 10.ed. São Paulo: Atlas, 2017.

FOUCAULT, Michel. Vigiar e punir: nascimento da prisão. Tradução de Raquel Ramalhete.

Petrópolis, Vozes, 1987.

HABERMAS, Jurgen. O futuro da natureza humana. A caminho de uma eugenia liberal?

Trad. Karina Janinni. São Paulo: Martinsfontes, 2010.

KRASILCHIK, Myriam. Reformas e Realidade: o caso do ensino das ciências. São Paulo em perspectiva. $\quad$ São $\quad$ Paulo. $2000 . \quad$ Disponível 〈http://www.scielo.br/pdf/spp/v14n1/9805.pdf>Acesso em: 06 ago 2018.

LEONEL, A.A.; SOUZA, C. A. Nanociência e Nanotecnologia para Ensino de Física Moderna e Contemporânea na Perspectiva da Alfabetização Científica e Técnica. In: Encontro Nacional de Pesquisa em Educação em Ciências. Florianópolis. 2009. Disponível em 〈http://posgrad.fae.ufmg.br/posgrad/viienpec/pdfs/1574.pdf>Ç> Acesso em 03 ago 2018.

LIMA, Fernando Rister de Souza. Sociologia do direito. O direito e o processo à luz da teoria dos sistemas de Niklas Luhmann. Curitiba: Juruá, 2009.

LUHMANN, Niklas. Sociologia do direito I. Tradução do original alemão de BAYER, Gustavo. Rio de Janeiro: Tempo Brasileiro, 1983. 
MOLLER. Letícia Ludwig. Esperança e responsabilidade: os rumos da bioética e do direito diante do progresso da ciência. In: COSTA, Judith Martins; Bioética e responsabilidade. (orgs). Rio de Janeiro: Forense, 2009, p 25-53.

PANTOJA, Najara Vidal. Nanociência, Nanotecnologia e Nanobiotecnologia: In: uma experiência de divulgação científica em Rio Branco - Acre. In: XVIII Encontro Nacional de Ensino de Química (XVIII ENEQ) Florianópolis, SC, 2016. Disponível em:< http://www.eneq2016.ufsc.br/anais/resumos/R1767-1.pdf> Acesso em: 03 ago 2018.

PIOVESAN, Flávia. Direitos humanos: desafios e perspectivas contemporâneas. Revista TST, v. 75, n.1, jan/mar 2009, p. 107-113.

RAMOS, André de Carvalho. Curso de direitos humanos. São Paulo : Saraiva, 2014.

REIS, Rafael Luís Vale e. O direito ao conhecimento das origens genéticas. Coimbra: Coimbra Editora, 2008.

REVENGA, Miguel; ROMBOLI, Roberto; SCAFF, Fernando Facury. A eficácia dos direitos sociais. São Paulo: Quartier Latin, 2009, p. 21-42.

SANTOS, José Manuel. O pensamento de Niklas Luhmann. Covilhã: Universidade da Beira Interior, 2005.

SARLET, Ingo Wolfgang. A eficácia dos diretos fundamentais. Uma teoria geral dos direitos fundamentais na perspectiva constitucional. 10.ed.Porto Alegre: Livraria do Advogado, 2009.

As dimensões da dignidade da pessoa humana: construindo uma compreensão jurídico-constitucional necessária e possível. Revista Brasileira de Direito Constitucional RBDC n. 09 - jan./jun. 2007, p. 361-388.

Comentários ao artigo $1^{\circ}$, III, da Constituição Federal. IN: CANOTILHO, José Joaquim Gomes; et. all. Comentários à Constituiçãa do Brasil. São Paulo: Saraiva/Almedina, 2013.

. Dignidade da pessoa humana e direitos fundamentais na constituição Federal de 1988. 7.ed., Porto Alegre: Livraria do Advogado, 2009.

Notas sobre a dignidade da pessoa humana na jurisprudência do Supremo Tribunal Federal. Rio de Janeiro: Lumen Iuris, Brasília 2011.

TORRES, Edgar Novoa. Las nuevas realidades del bios/zoe del cuerpo, entre la bioética y la biopolítica. Revista Latinoamericana de Bioética. v.14, n.1, ed. 26 , p. 98-114, 2014. Disponível em:<http://www.redalyc.org/pdf/1270/127031381008.pdf> Acesso em 01 ago 2018. 
